\title{
Preferences Based Stochastic Value and Utility Function Evaluation
}

\author{
Yuri P. Pavlov \\ Institute of Biophysics and Biomedical Engineering, \\ Bulgarian Academy of Sciences, Sofia, Bulgaria
}

yupavlov@clbme.bas.bg or yupavlov14@hotmail.com

\begin{abstract}
The expected utility theory is the approach to measurement and utilization of qualitative, conceptual information. The subject of this paper is creation of stochastic algorithms for evaluation of expert utility or value functions that give possibilities for development of value-driven decision support on the base of stochastic programming. An expert-computer dialogue is modeled and it realizes machine learning based on the Decision-maker's preferences.
\end{abstract}

Keywords: Expected utility, value, machine learning, preferences, stochastic programming.

\section{Introduction}

People preferences contain characteristics of uncertainty. The appearance of this uncertainty has subjective and probabilistic nature. This makes difficult the mathematical incorporation of human preferences in complex systems. The necessity of a merger of empirical knowledge with mathematical exactness causes troubles. Possible approach for solution of these problems is the stochastic approximation (Aizerman, Braverman, \& Rozonoer, 1970; Pavlov, 1989, 2005). The uncertainty of the subjective preferences could be viewed as a noise which can be eliminated as typical for the stochastic approximation procedures. A main requirement of the stochastic assessment is the analytical presentation of the qualitative nature of the human's preferences and notions (Aizerman et al., 1970; Keeney \& Raiffa, 1976; Raiffa, 1968; Vapnik, 1982).

This article deals with stochastic algorithms for evaluation of Decision-maker's (DM's) expected utility and value functions on the basis of expressed DM's preferences.

\section{Value function and value evaluation}

We begin with the simplest case, the construction of value functions (Fishburn, 1970; Keeney \& Raiffa, 1976). Let $\mathbf{X}$ be the set of alternatives $\left(\mathbf{X} \subseteq \mathbf{R}^{\mathrm{m}}\right)$. A "value" function is a function $\mathrm{u}^{*}$ (.) for which it is fulfilled (Keeney \& Raiffa, 1976):

Material published as part of this publication, either on-line or in print, is copyrighted by the Informing Science Institute. Permission to make digital or paper copy of part or all of these works for personal or classroom use is granted without fee provided that the copies are not made or distributed for profit or commercial advantage AND that copies 1) bear this notice in full and 2) give the full citation on the first page. It is permissible to abstract these works so long as credit is given. To copy in all other cases or to republish or to post on a server or to redistribute to lists requires specific permission and payment of a fee. Contact Publisher@InformingScience.org to request redistribution permission.

$$
\left.\left((x, y) \in \mathbf{X}^{2}, x\right\} y\right) \Leftrightarrow\left(u^{*}(x)>u^{*}(y)\right)
$$

The DM's preferences over $\mathbf{X}$ are expressed by $(\zeta)$. The real expert value function is denoted by $\mathrm{u}^{*}\left(\right.$.). Let $\mathbf{A}_{\mathbf{u}^{*}}$ and $\mathbf{B}_{\mathbf{u}^{*}}$ are the sets $\mathbf{A}_{\mathbf{u}^{*}}=\left\{(\mathrm{x}, \mathrm{y}) \in \mathbf{R}^{2 \mathrm{~m}} /\right.$ $\left.\left(\mathrm{u}^{*}(\mathrm{x})\right)>\mathrm{u}^{*}(\mathrm{y})\right\}, \mathbf{B}_{\mathrm{u}^{*}}=\left\{(\mathrm{x}, \mathrm{y}) \in \mathbf{R}^{2 \mathrm{~m}} /\right.$ $\left.\left(\mathrm{u}^{*}(\mathrm{x})\right)<\mathrm{u}^{*}(\mathrm{y})\right\}$. If there is a function $\mathbf{F}(\mathrm{x}, \mathrm{y})$ of the form $\mathbf{F}(\mathrm{x}, \mathrm{y})=\mathbf{f}(\mathrm{x})-\mathbf{f}(\mathrm{y})$, 
positive over $\mathbf{A}_{\mathbf{u}^{*}}$ and negative over $\mathbf{B}_{\mathbf{u}^{*}}$, then the function $\mathbf{f}(\mathrm{x})$ is a value function equivalent to the empirical DM's function value $u^{*}$ (.). In the deterministic case it is true that $\mathbf{A}_{\mathbf{u}^{*}} \cap \mathbf{B}_{\mathbf{u}^{*}}=\varnothing$ (Aizerman, Braverman, \& Rozonoer, 1970; Pavlov, 2005). The following recurrent procedure evaluate the function $\mathbf{F}(\mathrm{x}, \mathrm{y})=\mathbf{f}(\mathrm{x})-\mathbf{f}(\mathrm{y})$ :

$$
\begin{aligned}
\mathrm{F}_{\mathrm{n}+1}(x, \mathrm{y})= & \mathrm{F}_{\mathrm{n}}(\mathrm{x}, \mathrm{y})+\operatorname{sign}\left(\operatorname{sign}\left(\mathrm{u} *\left(\mathrm{x}_{\mathrm{n}+1}\right)-\mathrm{u} *\left(\mathrm{y}_{\mathrm{n}+1}\right)\right)-\operatorname{sign}\left(\mathrm{F}_{\mathrm{n}}\left(\mathrm{x}_{\mathrm{n}+1}, \mathrm{y}_{\mathrm{n}+1}\right)\right)\right) \times \\
& \times \mathrm{K}\left((\mathrm{x}, \mathrm{y}),\left(\mathrm{x}_{\mathrm{n}+1}, \mathrm{y}_{\mathrm{n}+1}\right)\right) .
\end{aligned}
$$

The function $\mathrm{K}\left((\mathrm{x}, \mathrm{y}),\left(\mathrm{x}_{\mathrm{n}+1}, \mathrm{y}_{\mathrm{n}+1}\right)\right)$ is a symmetric one with regard to the variables $(\mathrm{x}, \mathrm{y})$. The following is fulfilled for $\mathrm{K}((.,),.(.,)$.$) :$

$$
\mathrm{K}\left((\mathrm{x}, \mathrm{y}),\left(\mathrm{x}_{\mathrm{n}+1}, \mathrm{y}_{\mathrm{n}+1}\right)\right)=\Phi\left(\mathrm{x}_{\mathrm{n}+1}, \mathrm{x}\right)+\Phi\left(\mathrm{y}, \mathrm{y}_{\mathrm{n}+1}\right) .
$$

The function $\Phi(\mathrm{x}, \mathrm{y})$ fulfils:

$$
\Phi(\mathrm{x}, \mathrm{y})=\Phi(\mathrm{y}, \mathrm{x}), \Phi(\mathrm{x}, \mathrm{x})>\Phi(\mathrm{x}, \mathrm{y})>0 \text {, for } \forall(\mathrm{x}, \mathrm{y}) \in \mathbf{R}^{2 \mathrm{~m}}, \max |\Phi(\mathrm{x}, \mathrm{x})|<\mathrm{C}, \mathrm{C} \in \mathbf{R} \text {. }
$$

A possible choice of the function $\Phi(\mathrm{x}, \mathrm{y})$ is (Aizerman, Braverman, E. \& Rozonoer, 1970):

$$
\Phi(x, y)=e^{-\alpha\|x-y\|_{m}^{2}},(x, y) \in \mathbf{R}^{m} x \mathbf{R}^{m}, \alpha \in \mathbf{R}, \alpha>0 .
$$

We need the following definition. A "learning sequence" is a finite sequence of points $(\mathrm{x}, \mathrm{y}) \in \mathbf{R}^{2 \mathrm{~m}}$, $\left((\mathrm{x}, \mathrm{y})_{1},(\mathrm{x}, \mathrm{y})_{2}, \ldots,(\mathrm{x}, \mathrm{y})_{\mathrm{k}}, \ldots,(\mathrm{x}, \mathrm{y})_{\mathrm{n}, \ldots .}\right)$ for which the DM's preferences are expressed "a priori"$\left(\left(\mathrm{u}^{*}(\mathrm{x})\right)>\mathrm{u}^{*}(\mathrm{y})\right)$ or $\left.\left(\mathrm{u}^{*}(\mathrm{x})\right)<\mathrm{u}^{*}(\mathrm{y})\right)$. Any point $(\mathrm{x}, \mathrm{y}) \in \mathbf{R}^{2 \mathrm{~m}}$ of the "learning sequence" for which it is fulfilled $\left(\operatorname{sign}\left(\mathrm{F}^{\mathrm{n}}(\mathrm{x}, \mathrm{y})\right) \neq \operatorname{sign}\left(\mathrm{u}^{*}(\mathrm{x})-\mathrm{u}^{*}(\mathrm{y})\right)\right)$ is named "learning point". Then the following proposition is true.

Proposition 1: If the function $F^{n}(x, y)$ is constructed by the recurrent procedure (1) and $(x, y)$ is a "learning point" for $\mathrm{F}^{\mathrm{n}}(\mathrm{x}, \mathrm{y})$ then $(\mathrm{y}, \mathrm{x})$ is a "learning point" for $\mathrm{F}^{\mathrm{n}+1}(\mathrm{x}, \mathrm{y})$ in the next $(\mathrm{n}+1)^{\mathrm{th}}$ step. It is true that $\mathrm{F}^{2 \mathrm{k}}(\mathrm{x}, \mathrm{y})=\mathrm{f}^{2 \mathrm{k}}(\mathrm{x})-\mathrm{f}^{2 \mathrm{k}}(\mathrm{y})$ at each $(2 \mathrm{k})^{\mathrm{th}} \operatorname{step}\left(\mathrm{F}^{0}(\mathrm{x}, \mathrm{y})=0\right)$.

The proof is by recurrence. It is supposed that the "learning sequence" is uniformly distributed. It is well known that the procedure (1) finishes for a finite number of steps (k) if $\left(\mathbf{A}_{\mathbf{u}^{*}} \cap \mathbf{B}_{\mathbf{u}^{*}}=\varnothing\right)$ and $\left.\left(\left(\mathrm{u}^{*}(\mathrm{x})\right)-\mathrm{u}^{*}(\mathrm{y})\right)>\varepsilon, \varepsilon \in \mathbf{R}, \varepsilon>0\right)$ (Novikoff's theorem) (Aizerman, Braverman, \& Rozonoer, 1970). The function $\mathrm{F}^{2 \mathrm{k}}(\mathrm{x}, \mathrm{y})=\mathrm{f}^{2 \mathrm{k}}(\mathrm{x})-\mathrm{f}^{2 \mathrm{k}}(\mathrm{y})$ is positive over $\mathbf{A}_{\mathbf{u}^{*}}$ and the function $\mathrm{f}^{2 \mathrm{k}}(\mathrm{x})$ is an approximation of the expert value, because the procedure (1) recognizes the "learning sequence". The algorithm has the following explicit form:

$$
\begin{gathered}
u^{n}(x)=u^{n-1}(x)+\operatorname{sign}\left(\operatorname{sign}\left(u^{*}\left(x_{n}\right)-u^{*}\left(y_{n}\right)\right)-\operatorname{sign}\left(u^{n}\left(x_{n}\right)-u^{n}\left(y_{n}\right)\right)\right)\left(\Phi\left(x, x_{n}\right)-\Phi\left(x, y_{n}\right)\right), \\
\left(y_{n}, x_{n}\right) \in D, D=\mathbf{A}_{\mathbf{u}^{*}} \cup \mathbf{B}_{\mathbf{u}^{*}}, x \in \mathbf{R}^{\mathbf{m}} .
\end{gathered}
$$

The following theorem determines a stopping rule for this algorithm (Aizerman, Braverman, \& Rozonoer, 1970).

Theorem 1: The value function $u($.$) constructed with procedure (1) recognizes correctly (1-$ $\beta) 100 \%$ of the set $A_{u^{*}} \cup B_{u^{*}}\left(A_{u^{*}} \cap B_{u^{*}}=\varnothing\right)$ with probability grater then (1- $\left.\delta\right)$, if after the $i^{\text {th }}$ mistake $\left(\operatorname{sign}\left(u^{*}\left(x_{n}\right)-u^{*}\left(y_{n}\right)\right) \neq \operatorname{sign}\left(u^{n-1}\left(x_{n}\right)-u^{n-1}\left(y_{n}\right)\right)\right)$, the next $\left(L_{0}+i\right)$ points are recognized correctly $\left(\operatorname{sign}\left(u^{*}\left(x^{n}\right)-u^{*}\left(y_{n}\right)\right)=\operatorname{sign}\left(u^{n-1}\left(x_{n}\right)-u^{n-1}\left(y_{n}\right)\right)\right)$. The learning points $(x, y) \in \mathbf{R}^{m} x \mathbf{R}^{m}$ are uniformly distributed. The number $L_{0}$ fulfils the condition:

$$
L_{0} \geq \frac{\ln (\beta . \delta)}{\ln (l-\beta)} .
$$

The convergence of the procedure (6) is discussed in (Aizerman, Braverman, \& Rozonoer, 1970). 
It is well known that the value function is determined in the ordinal scale. Such an approximation $u^{\text {n }}\left(\right.$.) of the DM's value $u^{*}($.) permits analytical determination of the extremal points (the most preferred DM's alternatives). The probabilistic case $\left(\mathbf{A}_{\mathbf{u}^{*}} \cap \mathbf{B}_{\mathbf{u}^{*}} \neq \varnothing\right)$ is discussed in Aizerman, Braverman, and Rozonoer (1970) and Pavlov (1989, 2005).

\section{Expected Utility Evaluation}

More difficult is the utility evaluation. Let $\mathbf{X}$ be a set of alternatives and $\mathbf{P}$ is a subset of discrete probability distributions over $\mathbf{X}$. A utility function is any function $\mathrm{u}($.) for which it is fulfilled (Fishburn, 1970):

$$
\left.(\mathrm{p}\} \mathrm{q},(\mathrm{p}, \mathrm{q}) \in \mathbf{P}^{2}\right) \Leftrightarrow\left(\left(\int \mathrm{u}(.) \mathrm{dp}>\int \mathrm{u}(.) \mathrm{dq}\right), \mathrm{p} \in \mathbf{P}, \mathrm{q} \in \mathbf{P}\right) .
$$

According Von Neumann and Morgenstern the above formula means that the mathematical expectation of $\mathrm{u}($.$) is a quantitative measure concerning the expert's preferences for probability dis-$ tributions P over X (Fishburn, 1970; Keeney \& Raiffa, 1976; Raiffa, 1968). The DM's preferences over $\mathbf{P}$, including those over $\mathbf{X},(\mathbf{X} \subseteq \mathbf{P})$ are expressed by (\}$)$. The "indifference" relation $(\approx)$ is defined by $((x \approx y) \Leftrightarrow \neg((x\} y) \vee(x\{y)))$. It is well known that the existence of an utility function $\mathrm{u}($.$) over \mathbf{X}$ determines the "preference" relation $(\zeta)$ as a negatively transitive and asymmetric one (Fishburn, 1970):

Proposition 2: If $(\zeta)$ is negatively transitive relation the "indifference" relation $(\approx)$ is transitive.

Consequence: If the relation $(\zeta)$ is negatively transitive and reflexive the "indifference" relation $(\approx)$ is an "equivalence".

Every discrete probability distribution over $\mathbf{X}$ is called a "lottery". We mark the lottery as $\langle x, y, \alpha\rangle$, where $\alpha$ is the probability of the appearance of the alternative $x$ and (1- $\alpha$ ) - the probability of the alternative $y$. The most used approach in assessment of the utility uses the following comparisons: $(z \approx<x, y, \infty>)$, where $(x\} z\} y), \alpha \in[0,1],(x, y, z) \in X^{3}$ (Farquhar, 1984; Keeney \& Raiffa, 1976; Raiffa, 1968). The weak points of these approaches are the so called "certainty effect" and "probability distortion" identified by Kahneman and Tversky (Cohen, \& Jaffray, 1988; Mengov, 2010). The determination of the best alternative $x$ and the worst alternative $y$ on condition that $(x \nmid z\} y)$ where $\mathrm{z}$ is the analyzed alternative is not easy. The transitivity violations the "indifference" relation leads to the declinations in the assessments (Cohen, \& Jaffray, 1988). They explain the DM behaviour observed in the famous Allais Paradox that arises from the "independence" axiom (Fishburn, 1970):

$$
\left.\left(p \nmid q, 0<\alpha<1,(p, q, r) \in \boldsymbol{P}^{3}\right) \Rightarrow((\alpha p+(1-\alpha) r)\}(\alpha q+(1-\alpha) r)\right) \text {. }
$$

Starting from the properties of the preference relation $(\zeta)$ and indifference relation $(\approx)$ we propose the next stochastic approximation procedure for evaluation of the utility function $u($.$) . It is as-$ sumed that $(\boldsymbol{X} \subseteq \boldsymbol{P}),\left((q, p) \in \boldsymbol{P}^{2} \Rightarrow(\alpha q+(1-\alpha) p) \in \boldsymbol{P}\right.$, for $\left.\forall \alpha \in[0,1]\right)$ and that the utility function $u($.$) exists. We define two sets: \boldsymbol{A}_{\boldsymbol{u}^{*}}=\left\{(\alpha, x, y, z) /\left(\alpha u^{*}(\mathrm{x})+(1-\alpha) u^{*}(y)\right)>u^{*}(z)\right\}$ and $\boldsymbol{B}_{\boldsymbol{u}^{*}}=\left\{(\alpha, x, y, z) /\left(\alpha u^{*}(x)+(1-\alpha) u^{*}(y)\right)>u^{*}(z)\right\}$, where $u^{*}($.$) is the DM's empirical utility. The utility$ function $u($.$) over \boldsymbol{X}$ is determined with the accuracy of the affine transformation (interval scale), according to the following proposition (Fishburn, 1970):

Proposition 3: If $(x \in X,((p(x)=1) \Rightarrow(p \in \boldsymbol{P})))$ and $\left((q, p) \in \boldsymbol{P}^{2} \Rightarrow(\alpha p+(1-\alpha) q) \in \boldsymbol{P}, \alpha \in[0,1]\right)$ are realized, then $u($.$) is defined with precision up to the affine transformation \left(u_{1}(.) \approx u_{2}().\right) \Leftrightarrow$ $\left(u_{1}()=.a u_{2}()+b,. a>0 \wedge b \in \boldsymbol{R}\right)$.

The first condition can be interpreted as an expert's opportunity to imagine every single alternative, the second condition - as an expert's opportunity to report on the probability uncertainty of 
the results. This proposition allows decomposition of the multiattribute utility in to more simple functions (Keeney \& Raiffa, 1976).

The following proposition is in the foundation of the proposed stochastic approximation procedures (Pavlov, 2005):

Proposition 4: We denote $\mathbf{A}_{\mathrm{u}}=\{(\alpha, \mathrm{x}, \mathrm{y}, \mathrm{z}) /(\alpha \mathrm{u}(\mathrm{x})+(1-\alpha) \mathrm{u}(\mathrm{y}))>\mathrm{u}(\mathrm{z})\}$. If $\mathrm{A}_{\mathrm{u} 1}=\mathrm{A}_{\mathrm{u} 2}$ than $\mathrm{u}_{1}()=.\mathrm{au}_{2}()+.\mathrm{b}, \mathrm{a}>0$.

Proposition 4 presents a possible approach to utility evaluation (approximation of the set $\mathbf{A}_{\mathbf{u}^{*}}$ ) (Aizerman, Braverman, \& Rozonoer, 1970; Pavlov, 2005). The expert utilities could be evaluated by "pattern recognition" of $\mathbf{A}_{\mathbf{u}^{*}}$ with a computer learning procedure using the DM's preferences (Aizerman, Braverman, \& Rozonoer, 1970). The proposed machine learning is a probabilistic pattern recognition $\left(\boldsymbol{A}_{\boldsymbol{u}^{*}} \cap \boldsymbol{B}_{u^{*}} \neq \varnothing\right)$ and the utility evaluation is a stochastic approximation with noise (uncertainty) elimination. Key element is the proposition 4.

\section{The following presents the evaluation procedure:}

The DM compares the "lottery" $<x, y, \alpha>$ with the simple alternative $z, z \in \boldsymbol{Z}$ ("better- $\}$, $f(x, y, z, \alpha)=1$ ", "worse- $\{, f(x, y, z, \alpha)=1$ " or "can't answer or equivalent- $\sim, f(x, y, z, \alpha)=0$ ", $f()$. denotes the qualitative DM answer $)$. This determines a learning point $((x, y, z, \alpha), f(x, y, z, \alpha))$. The stochastic algorithm constructs the utility polynomial approximation $u(x)=\sum_{i} c_{i} \Phi_{i}(x)$ (Aizerman, Braverman, \& Rozonoer, 1970; Pavlov, 2005):

$$
\begin{aligned}
& c_{i}^{n+1}=c_{i}^{n}+\gamma_{n}\left[f\left(t^{n+1}\right)-\overline{\left(c^{n}, \Psi\left(t^{n+1}\right)\right)}\right] \Psi_{i}\left(t^{n+1}\right), \\
& \sum_{n} \gamma_{n}=+\infty, \sum_{n} \gamma_{n}^{2}<+\infty, \forall n, \gamma_{n}>0
\end{aligned}
$$

In the formula the following notations (based on $\left.\mathbf{A}_{\mathbf{u}}\right)$ are used: $\mathbf{t}=(\mathrm{x}, \mathrm{y}, \mathrm{z}, \alpha)$, $\psi_{\mathrm{i}}(\mathrm{t})=\psi_{\mathrm{i}}(\mathrm{x}, \mathrm{y}, \mathrm{z}, \alpha)=\alpha \Phi_{\mathrm{i}}(\mathrm{x})+(1-\alpha) \Phi_{\mathrm{i}}(\mathrm{y})-\Phi_{\mathrm{i}}(\mathrm{z})$, where $\left(\Phi_{\mathrm{i}}(\mathrm{x})\right)$ is a family of polynomials. The line above $\overline{\mathrm{y}}=\left(\mathrm{c}^{\mathrm{n}}, \Psi(\mathrm{t})\right)$ means: $(\overline{\mathrm{y}}=1)$, if $(\mathrm{y}>1),(\overline{\mathrm{y}}=-1)$ if $(\mathrm{y}<-1)$ and $(\overline{\mathbf{y}}=\mathbf{y})$ if

$(-1<\mathrm{y}<1)$. The $c_{\mathrm{i}}^{\mathrm{n}}$ take part in the decomposition $g^{n}(x)=\sum_{i=1}^{n} c_{i}^{n} \Phi_{i}(x)$ and

$$
\left(c^{n}, \Psi(t)\right)=\alpha g^{n}(x)+(1-\alpha) g^{n}(y)-g^{n}(z)=G^{n}(x, y, z, \alpha) \text { is a scalar product. }
$$

\section{The mathematical procedure describes the following assessment process:}

The DM relates the "learning point" $(x, y, z, \alpha))$ to the set $\boldsymbol{A}_{\mathbf{u}^{*}}$ with probability $\mathrm{D}_{1}(x, y, z, \alpha)$ or to the set $\boldsymbol{B}_{\mathbf{u}^{*}}$ with probability $\mathrm{D}_{2}(x, y, z, \alpha)$. The probabilities $\mathrm{D}_{1}(x, y, z, \alpha)$ and $\mathrm{D}_{2}(x, y, z, \alpha)$ are mathematical expectation of $f\left(\right.$. over $\boldsymbol{A}_{\boldsymbol{u}^{*}}$ and $\boldsymbol{B}_{\boldsymbol{u}^{*}}$ respectively, $\left(\mathrm{D}_{1}(x, y, z, \alpha)=\mathrm{M}(f / x, y, z, \alpha)\right)$ if $(\mathrm{M}(f / x, y, z, \alpha)>0)$, $\left(\mathrm{D}_{2}(x, y, z, \alpha)=(-) \mathrm{M}(f / x, y, z, \alpha)\right)$ if $(\mathrm{M}(f / x, y, z, \alpha)<0)$. Let $\mathrm{D}^{\prime}(x, y, z, \alpha)$ is the random value: $\mathrm{D}^{\prime}(x, y, z, \alpha)=\mathrm{D}_{1}(x, y, z, \alpha)$ if $(\mathrm{M}(f / x, y, z, \alpha)>0) ; \mathrm{D}^{\prime}(x, y, z, \alpha)=\left(-\mathrm{D}_{2}(x, y, z, \alpha)\right)$ if $(\mathrm{M}(f / x, y, z, \alpha)<0)$; $\mathrm{D}^{\prime}(x, y, z, \alpha)=0$ if $(\mathrm{M}(f / x, y, z, \alpha)=0)$. We approximate $\mathrm{D}^{\prime}(x, y, z, \alpha)$ by a function of the type : $\mathrm{G}(x, y, z, \alpha)=(\alpha \mathrm{g}(x)+(1-\alpha) \mathrm{g}(y)-\mathrm{g}(z))$, where $g(x)=\sum_{i} c_{i} \Phi_{i}(x)$.

The coefficients $c_{i}^{n}$ take part in the polynomial approximation of $\mathrm{G}(x, y, z, \alpha)$ : 


$$
\mathrm{G}^{n}(x, y, z, \alpha)=\left(c^{n}, \Psi(t)\right)=\alpha g^{n}(x)+(1-\alpha) g^{n}(y)-g^{n}(z), g^{n}(x)=\sum_{i=1}^{N} c_{i}^{n} \Phi_{i}(x) .
$$

The function $\mathrm{G}^{\mathrm{n}}(x, y, z, \alpha)$ is positive over $\boldsymbol{A}_{\boldsymbol{u}^{*}}$ and negative over $\boldsymbol{B}_{\boldsymbol{u}^{*}}$ depending on the degree of approximation of $\mathrm{D}^{\prime}(x, y, z, \alpha)$. The approximation of the utility function $\mathbf{u}($.$) is the function$ $\boldsymbol{g}^{\mathbf{n}}(\boldsymbol{x})$. The stochastic procedure has the following explicate form:

$$
\begin{aligned}
& c_{i}^{n+1}=c_{i}^{n}+\gamma_{n}\left[\mathrm{D}^{\prime}\left(t^{n+1}\right)+\xi^{n+1}-\overline{\left(c^{n}, \Psi\left(t^{n+1}\right)\right)}\right] \Psi_{i}\left(t^{n+1}\right), \\
& \sum_{n} \gamma_{n}=+\infty, \sum_{n} \gamma_{n}^{2}<+\infty, \forall n, \gamma_{n}>0 . \\
& f\left(t^{n+1}\right)=\left[\mathrm{D}^{\prime}\left(t^{n+1}\right)+\xi^{n+\eta} .\right.
\end{aligned}
$$

The stochastic convergence of the procedure is described and is analyzed in (Aizerman, Braverman, \& Rozonoer, 1970). The following theorem determines the convergence (Pavlov, 2005):

Theorem 2: We denote by $\left(t^{1}, \ldots, t^{\mathrm{n}}, ..\right)$ a sequence of independent random vectors $t=(x, y, z, \alpha)$ with one and the same distribution $\mathrm{F}$. We suppose that the sequence of random values $\left(\xi^{1}, \xi^{2}, . \xi^{\mathrm{n}}, ..\right)$ satisfies the conditions: $\quad \mathrm{M}\left(\xi^{\mathrm{n}} /(x, y, z, \alpha), c^{\mathrm{n}-1}\right)=0, \mathrm{M}\left(\left(\xi^{\mathrm{n}}\right)^{2} /(x, y, z, \alpha), c^{\mathrm{n}-1}\right)<\mathrm{d}, \mathrm{d} \in R$. It is supposed that the Euclidian norm of $\Psi(t)$ is limited by a constant, $\|\Psi(t)\|<\theta, \theta \in \boldsymbol{R}, \theta>0$, for $\forall t, t=(x, y, z, \alpha)$. The convergence follows from procedure (10):

$$
\begin{aligned}
& \mathrm{J}_{D^{\prime}}\left(\mathrm{G}^{\mathrm{n}}(x, y, z, \alpha)\right)=\mathrm{M}\left(\int_{\mathrm{D}^{\prime}(t)}^{\mathrm{G}^{\mathrm{n}}(t)}\left(\overline{\mathrm{v}}-\mathrm{D}^{\prime}(t)\right) \mathrm{dv}\right)=\int\left(\int_{\mathrm{D}^{\prime}(t)}^{\mathrm{G}^{\mathrm{n}}(\mathrm{t})}\left(\overline{\mathrm{v}}-\mathrm{D}^{\prime}(t)\right) \mathrm{dv}\right) \mathrm{dF} \stackrel{p \cdot p .}{n} \\
& -\frac{p \cdot p .}{n} \rightarrow \inf _{S(t)} \int\left(\int_{\mathrm{D}^{\prime}(t)}^{S(t)}\left(\overline{\mathrm{v}}-\mathrm{D}^{\prime}(t)\right) \mathrm{dv}\right) \mathrm{dF} \quad .
\end{aligned}
$$

In the theorem above p.p. denotes "almost sure" and $\mathrm{M}$ denotes mathematical expectation. The functions $S(t)$ in the limits of the integral belong to $\mathrm{L}_{2}$ (defined by the probability measure $\mathrm{F}$ ) and have the presentation described by formula (11). The integral $J_{D^{\prime}}\left(G^{n}(x, y, z, \alpha)\right)$ fulfills:

$$
\int\left(\int_{D^{\prime}(t)}^{G^{n}(t)}\left(\bar{v}-D^{\prime}(t)\right) \mathrm{dv}\right) \mathrm{dF} \geq \frac{1}{2} \int\left(\overline{G^{n}(t)}-\mathrm{D}^{\prime}(t)\right)^{2} \mathrm{dF} .
$$

The proof is based on the "extremal approach" of the "potential function method" (Aizerman, Braverman, \& Rozonoer, 1970). The learning points $((x, y, z, \alpha), f(x, y, z, \alpha))$ are set with a pseudo random sequence.

The proposed procedure and its modifications are machine learning. The DM is comparatively fast in learning to operate with the procedure: a session with 128 questions (learning points) takes approximately 45 minutes and requires only qualitative answers "yes", "no" or "equivalent".

\section{Assessment of the Empirical Risk and Modeling of the Dialog DM-Computer}

The empirical risk regarding Vapnik can be assessed with the function $G^{n}(x, y, z, \alpha)$ (Vapnik, 1982). The utility function approximation $g^{n}(x)=\sum_{i=1}^{n} c_{i}^{n} \Phi_{i}(x)$ is randomized between 0 and 1 
(proposition 3) and this causes the value $\operatorname{abs}\left(G^{n}(x, y, z, \alpha)\right)$ to be limited by 1 . The degree of the approximation polynomial $g(x)=\sum_{i=1}^{n} c_{i} \Phi_{i}(x)$ is denoted by $n$. The number of the "learning points" $(x, y, z, \alpha)$ in the learning sequence is denoted by $(l)$. The "empirical" probability $P_{e}\left(c_{i}\right)$ is assessed as $\left(n_{w} / l\right)$, where $n_{w}$ is the number of wrong answers in the process of machine learning. The probability $P\left(c_{i}\right)$ is the probability of possible "wrong recognition" by the computer on the base of the constructed utility function. According to (Vapnik, 1982) the following is true:

$$
P\left(c_{i}\right) \leq P_{e}\left(c_{i}\right)+2 \frac{\ln \left(\frac{1,5 l^{n}}{n !}\right)-\ln \left(\frac{\eta}{8}\right)}{l}\left(1+\sqrt{1+\frac{P_{e}\left(c_{i}\right) l}{\ln \left(\frac{1,5 l^{n}}{n !}\right)-\ln \left(\frac{\eta}{8}\right)}}\right)=P_{m}\left(c_{i}\right) .
$$

The above formula means that the probability $P\left(c_{i}\right)$ is smaller than the number $P_{m}\left(c_{i}\right)$ with probability grater than $(1-\eta)$ (in the case that $(l>n)$ ). Simple calculations show that this formula is useful in the case of $(l>1024)$. The presentation of the function $G^{n}(x, y, z, \alpha)$ gives a hint that this valuation could be improved. The full recognition is impossible because $\left(\boldsymbol{A}_{\boldsymbol{u}^{*}} \cap \boldsymbol{B}_{\boldsymbol{u}^{*}} \neq \varnothing\right)$.

The dialogue between the expert and the computer was modelled, the expert being replaced by a model function, the solid line in Figure 1 and Figure 2 (Pavlov, 2005).

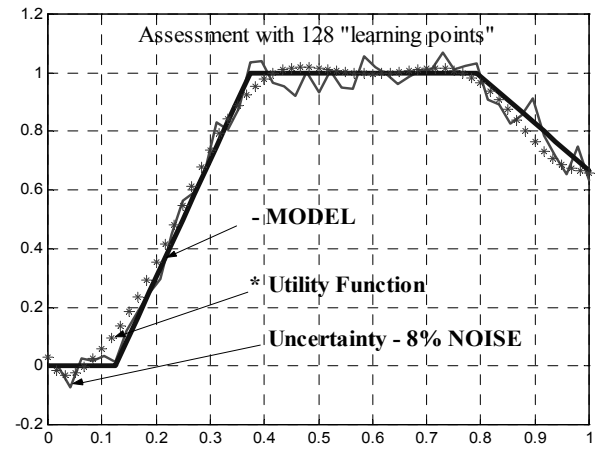

Figure 1: Evaluation, 128 "learning points"

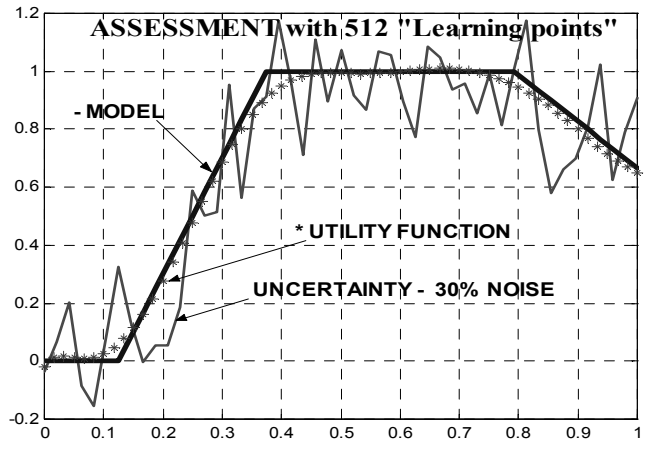

Figure 2: Evaluation, 512 "learning points"

In the modelling an additive noise determines the uncertainty in DM's answers. Finally the expert is modelled with the seesaw lines in Figure 1 and Figure 2. The learning points $(x, y, z, \alpha)$ are set with a pseudo-random $\mathrm{Lp}_{\tau}$ sequence.

Our approach permits assessment of the dependence of the utility function on probability. For this purpose, we search for an polynomial approximation with procedure (10) of the kind $u(x, \alpha)$, $\alpha \in[0,1], x \in \boldsymbol{X}$ following Kahneman and Tversky (theory of prospects) (Mengov, 2010). The explicit formula of the utility function $u(x)$ in this case is $u(x)=\int_{0}^{1} u(x, \alpha) d \alpha$. Example of such evaluated utility function $u(x, \alpha)$ is shown in Terzieva, Pavlov, and Andreev (2007). 


\section{Example of Application}

Example of application is assessment of student's preferences with respect to an exam form (Terzieva, Pavlov, \& Andreev 2007). The estimation of the preferences of a group of learners is performed by a decision support system for estimation of individual's utility functions developed on the basis of the presented mathematical formulations and methods in an environment that consists of Visual Studio, Visual Basic 6.0. The final calculations and graphics are performed in the MATLAB environment.

The objective of this example is the evaluation of the student's preferences for the form and style of the exam. The examination (A) -form concerns the way of knowledge expression by a student: "test" or "free expression". The examination (B) - style regards student's exam: "oral" and "written" (Terzieva, Pavlov, \& Andreev 2007). The possible criteria for the estimation of the preferences of students which satisfaction is the objective of the teacher during an examination are the followings: (A)-“\% test in relation to the entire examination material" $(0 \%$ to $100 \%)$, illustrated in Figure 3; (B)-“\% time for written exam in relation to the whole time that is necessary for this exam" ( $0 \%$ to $100 \%)$, illustrated in Figure 4 (Terzieva, Pavlov, \& Andreev 2007). The seesaw lines in Figure 3 and Figure 4 recognize correctly more then $95 \%$ of the answers.

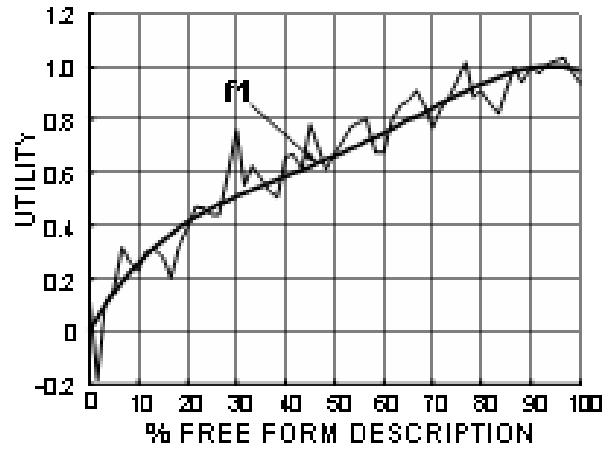

Figure 3: Utility $\mathrm{f}_{1}(\mathrm{x})$

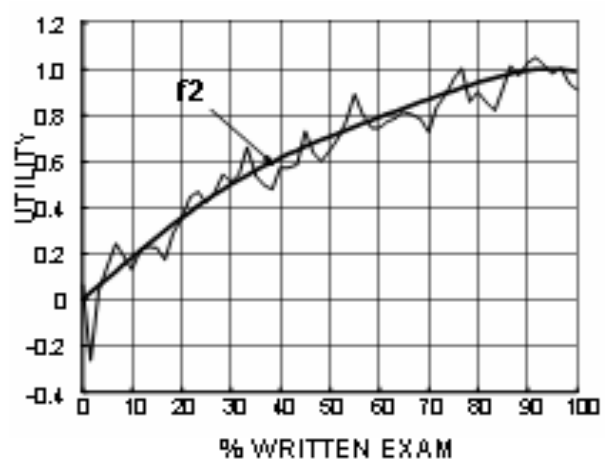

Figure 4: Utility $\mathrm{f}_{2}(\mathrm{x})$

Since the teacher accepts that the factors (A) and (B) are mutual independent in relation to "utility", the utility function has the following expression (Keeney, \& Raiffa, 1976):

$\mathrm{U}(\mathrm{a}, \mathrm{b})=\mathrm{K}_{1} * \mathrm{f}_{1}(\mathrm{a})+\mathrm{K}_{2} * \mathrm{f}_{2}(\mathrm{~b})+\left(1-\mathrm{K}_{1}-\mathrm{K}_{2}\right) *\left(\mathrm{f}_{1}(\mathrm{a}) * \mathrm{f}_{2}(\mathrm{~b})\right),(\mathrm{a}, \mathrm{b} \in[0,100] \%)$.

The determination of the coefficients $K_{1}$ and $K_{2}$ depends on the determination of $f_{1}($.$) and f_{2}($.$) .$ This utility function is presented by the Figure 5 and Figure 6 (Terzieva, Pavlov, \& Andreev 2007).

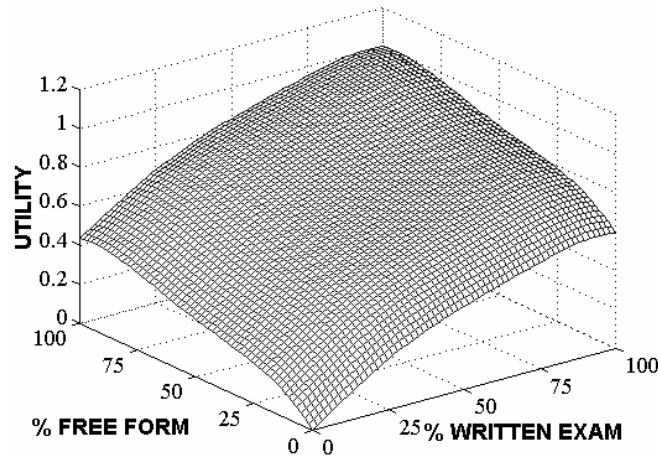

Figure 5: Teacher Utility

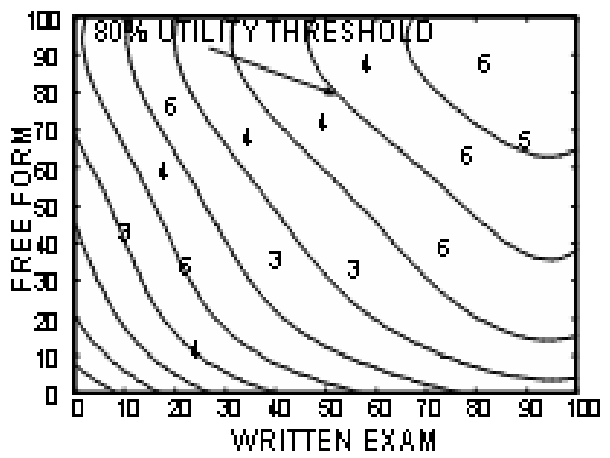

Figure 6: Partition of student's group 
The Figure 6 illustrates the lines of identical preferences that show a way for partition the group of students in subgroups in accordance with their identical preferences. We can determine to which subgroup belongs a student through the construction of his $f_{1}($.$) and f_{2}($.$) . They are a source$ for the determination of $\mathrm{a}_{\max }$ and $\mathrm{b}_{\max }$ and $\mathrm{U}\left(\mathrm{a}_{\max }, \mathrm{b}_{\max }\right)$ that shows the position of the student in the space presented by Figure 6, i.e. the subgroup to which the student belongs.

Applications and discussions was carred out in Bulgarian Academy of Sciences in a continuous succession in the area of the Decision support systems and Control theory (Pavlov, 1989, 2000, 2005).

\section{Conclusions}

The experiments confirm the applicability of the approach. The following points should be highlighted:

- $\quad$ After explaining the term "lottery", DM is relatively quick in learning the suggested methods according his/her qualification level.

- $\quad$ The recurrent nature of the procedures facilitates their computer implementations (the questions are similar and require only qualitative answers).

- $\quad$ This method permits practical use of expert information, value or utility functions and the evaluation is machine-learning based on DM's preferences.

- $\quad$ The suggested approach can be regarded as a realization of the prescriptive decision making approach.

The utility function is an abstraction presented in the limits of the normative approach, the axiomatic systems of Von Neumann. In the paper is revealed the existence of a mathematical expectation measured in the interval scale on the base of the DM's preferences (proposition 4 - If $\mathrm{A}_{\mathrm{u} 1}=\mathrm{A}_{\mathrm{u} 2}$ than $\left.\mathrm{u}_{1}()=.\mathrm{au}_{2}()+.\mathrm{b}, \mathrm{a}>0\right)$. This mathematical expectation could be interpreted as an approximation of the expected utility function.

\section{References}

Aizerman, M. A., Braverman, E., \& Rozonoer, L. (1970). Potential function method in the theory of machine learning (Метод потенциальних функций в теори обуюения машин). Moscow: Nauka.

Cohen, M., \& Jaffray, J.Y. (1988). Certainty effects versus probability distortion: An experimental analysis of decision making under risk. Journal of Experimental Psychology: Human Perceptions and Performance, 14(4), 554-560.

Farquhar, P. (1984). Utility assessment methods. Management Science, 30, 1283-1300.

Fishburn, P.C. (1970). Utility theory for decision-making. New York: Wiley.

Keeney, R., \& Raiffa, H. (1976). Decision with multiple objectives: Preferences and value trade-offs. New York: Wiley.

Mengov G. (2010). Decision making under risk and uncertainty (Вземане на решения при риск и неопределеност). Sofia, Bulgaria: Publishing house"JANET 45".

Pavlov, Y. (1989). A recurrent algorithm for construction of value function. Proceedings of Bulgarian Academy of Sciences (Comptes rendus de L'Academie bulgare des Sciences), 7, 41-42.

Pavlov Y. (2000). Methods in decision support: Measurement, machine learning algorithms, applications in decision support systems and control theory. Sofia, Interdisciplinary Seminar on Biomathematics and Scientific Computations, Bulgarian Academy of Sciences. Retrieved from http://www.math.bas.bg/ bio/umb/seminars old.html 
Pavlov, Y. (2005). Subjective preferences, values and decisions. Stochastic Approximation Approach. Proceedings of Bulgarian Academy of Sciences (Comptes Rendus de l'Academie bulgare de Sciences), T. $58(4), 67-372$.

Raiffa, H. (1968). Decision analysis. Introductory lectures on choices under uncertainty. Addison-Wesley.

Terzieva V., Pavlov Y., \& Andreev R. (2007). E-learning usability: A learner-adapted approach based on the evaluation of learner's preferences. Publication (monograph): e-learning III and the knowledge society and Communication \& Cognition-Art. Intelligence, Belgium.

Vapnik, V. (1982). Estimation of dependencies based on empirical data. Springer Series in Statistics, Springer -Verlag New York, Inc Secaucus, NU, USA.

\section{Biography}

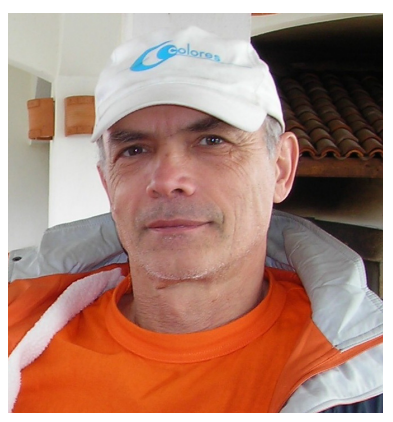

Associate professor Yuri Pavlov was born in Sofia, Bulgaria. He graduated his higher education from Paris VI (Math. et Phys.) and from Technical university of Sofia (Diploma in Automatics and Diploma in Applied mathematics) and Ph.D. on engineering (Automatics)Bulgarian Academy of Sciences. At present is Associate professor in Institute of Biophysics and Biomedical Engineering, Bulgarian Academy of Sciences. His scientific interests are in the fields of decision making and decision support, utility theory, theory of measurement (scaling), operational researches, optimization and optimal control (including complex systems). Most Important Achievements are the fol-

lowing:

- Nonlinear mathematical models of fermentation processes are developed and investigated. New methodology for exact linearization of nonlinear dynamic models via optimization methods is developed.

- Sophisticated algorithms for utility assessment and expert preferences based machine learning are developed. The subjective and probability uncertainty of expert preferences are interpreted as noise and the stochastic programming is used for recurrent evaluation of the utility functions with noise elimination as typical for stochastic procedures. This could be taken as a realization of the prescriptive decision making approach.

- A machine learning methodology for development of expert utility-based decision support is created. The computer approach for obtaining of expert qualitative and quantitative data (expert preferences) is developed for application in complex systems and processes with various forms of uncertainty, where human values (utility) are important for the final decisions.

http://www.clbme.bas.bg/ 